\title{
Mucocele salivar em bovino
}

\author{
Mucocele salivary in bovine
}

Angélica Link (D) ${ }^{1,2 *}$, Gabriela Anghinoni ${ }^{1}{ }^{1}$, Anabella Mira1 ${ }^{1}$ Ciro Meirelles ${ }^{1}$, Tiago Andre Frigotto (D)

${ }^{1}$ Pontifícia Universidade Católica do Paraná (PUCPR), Toledo, PR, Brasil

2 Universidade do Oeste de Santa Catarina (Unoesc), São Miguel do Oeste, SC, Brasil

\section{Resumo}

Mucocele é o acúmulo de saliva no tecido subcutâneo adjacente a uma glândula ou ducto salivar, ocasionando uma obstrução ou ruptura. Tal enfermidade é considerada rara na clínica médica de ruminantes, tendo poucos relatos na literatura. Esse trabalho tem por objetivo relatar um caso de mucocele salivar de glândula sublingual direita em um bovino, macho, mestiço, 1,5 anos, 250 kg, escore de condição corporal 2 ( 1 a 5). A queixa principal descrita pelo proprietário no atendimento clínico era de um aumento de volume no espaço intermandibular e sublingual, o qual dificultava a alimentação do animal há seis meses, resultando em emagrecimento progressivo. Após exame clínico e complementar, o diagnóstico definitivo foi de mucocele da glândula sublingual direita. O tratamento desta foi por meio da técnica cirúrgica de marsupialização da rânula, a qual objetivou drenar o acúmulo de saliva e evitar que se acumulasse novamente. O procedimento cirúrgico resultou em sucesso.

Palavras-chave: Ruminante. Glândula salivar. Obstrução de ducto. Marsupialização da rânula.

* Autor correspondente: angelicalink@hotmail.com

Submetido: 22 mai 2019 | Aprovado: 6 jan 2020

\begin{abstract}
The accumulation of saliva in the subcutaneous tissue adjacent to a salivary gland or duct causing an obstruction or rupture is defined as mucocele. Such disease is considered rare in the ruminant medical clinic, with few reports in the literature. The present study aims to report a case of salivary mucocele of the right sublingual gland in a male, mestizo, bovine, 1,5 years, $250 \mathrm{~kg}$, body condition score 2 (1 to 5). The main complaint described by the owner was an increase in volume in the intermandibular and sublingual space, which made it difficult to feed the animal six months ago, resulting in progressive weight loss. After anamnesis, clinical, physical and complementary examinations, the definitive diagnosis was mucocele of the right sublingual gland. The therapy instituted was the marsupialization of the cannula, which aimed to drain the accumulation of saliva and prevent accumulation again. The surgical procedure was successful.
\end{abstract}

Keywords: Ruminant. Salivary gland. Duct obstruction. Marsupialization of the solanum. 


\section{Introdução}

As glândulas salivares são órgãos pares responsáveis pela secreção da saliva dentro da cavidade oral através de seus ductos. A saliva tem a função de manter a mucosa oral úmida, misturarse ao alimento durante a mastigação, iniciar a digestão química do alimento e, em ruminantes, tem ainda a função de tamponamento ruminal (McDougall, 1948; Konig et al., 2011). A maioria dos mamíferos possui três pares de glândulas salivares: parótidas, mandibulares e sublinguais. Cada uma dessas drena saliva por um ducto principal, levando-a até a cavidade oral (Sisson et al., 1975; Dyce et al., 2010).

O acúmulo de saliva no tecido subcutâneo adjacente a uma glândula ou ducto salivaré definido como mucocele, podendo estar relacionado à obstrução ou ruptura do mesmo. Sua nomenclatura está associada à localização anatômica, sendo elas mucocele cervical, sublingual, faríngea, zigomática e mucocele complexa (Nelson e Couto, 2001; Hedlund, 2002; Santana et al., 2014).

A mucocele cervical é o acúmulo de saliva no espaço intermandibular mais profundo, ângulo da mandíbula ou região cervical superior. A mucocele sublingual, também denominada de rânula, é formada pelo acúmulo de saliva no tecido sublingual. A mucocele faríngea é formada em tecidos próximos à faringe e a zigomática se forma na região ventral ao globo ocular. A mucocele complexa é formada por dois ou mais tipos de mucocele (Hedlund, 2002; Radlinsky, 2014).

A etiologia da mucocele está associada a traumas, corpos estranhos, sialólitos e, muitas vezes, não é possível identificar a causa (Radlinsky, 2014). O extravasamento de saliva para os tecidos circunjacentes leva ao aparecimento de um processo inflamatório e, consequentemente, à formação de um tecido de granulação que circunda a saliva (Tommasi, 2014).

Os sinais clínicos se limitam a um aumento de volume macio e flutuante, associado ou não à dor no momento da mastigação, e seu diagnóstico é baseado no histórico, sinais clínicos, exame citológico e sialografia (Radlinsky, 2014).

A recidiva da mucocele ocorre frequentemente quando é feita a terapia apenas com aspiração e drenagem do conteúdo; desta forma, recomendase fazer a excisão cirúrgica das glândulas salivares acometidas. Quando se trata de rânula, opta-se inicialmente pela marsupialização, mas se houver recorrência, indica-se a sialoadenectomia (Neville et al., 2004; Tobias, 2011). De forma geral, o prognóstico é favorável (Dias et al., 2013).

O presente trabalho tem por objetivo relatar um caso de mucocele salivar em um bovino atendido na rotina da Clínica Veterinária Universitária da Pontifícia Universidade Católica do Paraná Campus Toledo.

\section{Relato de caso}

Foi atendido um bovino, macho, mestiço, 1,5 anos, $250 \mathrm{~kg}$, escore de condição corporal (ECC) 2. $\mathrm{Na}$ anamnese, o proprietário relatou que há aproximadamente seis meses o animal apresentou aumento de volume do espaço intermandibular (papeira)(Figura 1A), instituindo, por conta própria, tratamento na propriedade à base de ivermectina $(0,2 \mathrm{mg} / \mathrm{kg} / \mathrm{SC})$ e iodeto de potássio $(4 \mathrm{mg} / \mathrm{kg} / \mathrm{IM})$, porém, sem regressão.

O proprietário somente solicitou atendimento clínico após ter percebido a ineficiência do tratamento inicial e por ter observado um aumento de volume no interior da cavidade oral no espaço sublingual (Figura 1B), o que dificultava a apreensão e a alimentação normal do animal, intensificando o emagrecimento do paciente. $O$ animal permanecia na propriedade, junto com o rebanho bovino, em piquete de Tifton 85 , sendo este o alimento volumoso consumido via pastejo, recebendo em cocho suplemento concentrado à base de farelo de soja e milho, além de suplemento mineral e água ad libitum.

No exame clínico geral, o animal se apresentava em estação, atento e sem alterações nos parâmetros vitais. No exame físico da cavidade oral, verificouse a presença da rânula, ou seja, um pseudocisto com aumento volumétrico circunscrito medindo aproximadamente $5 \mathrm{~cm}$ de diâmetro, liso, flácido, translúcido e sem resposta dolorosa na palpação, distribuído em toda a extensão do espaço intermandibular e abaixo da língua, o qual drenava um fluído viscoso com coloração transparente. 

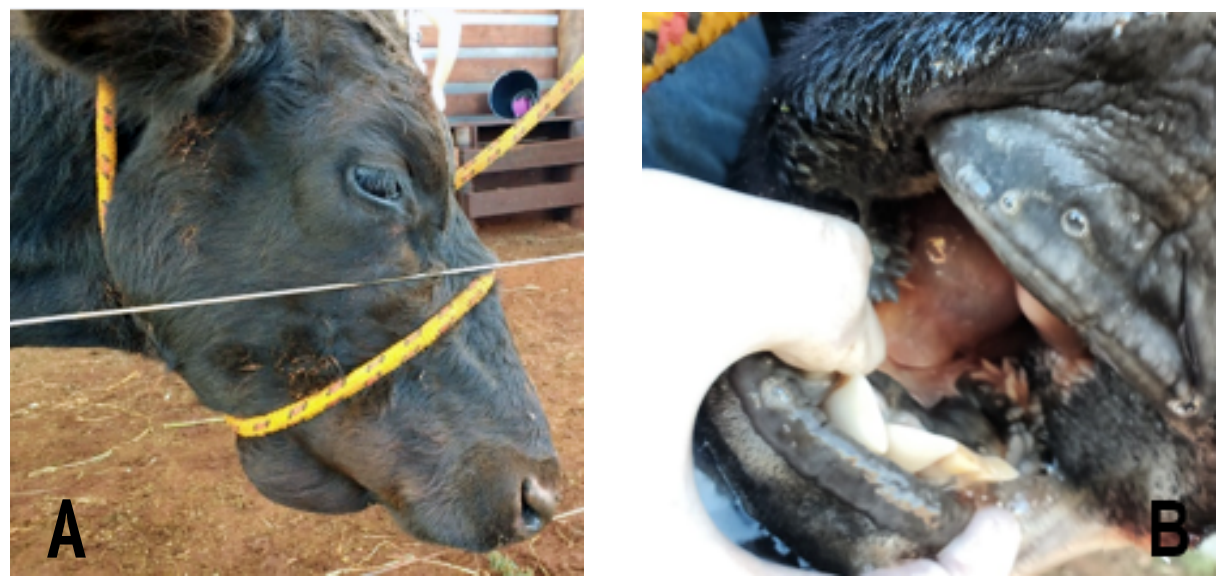

Figura 1 - Exame clínico. A - Bovino, mestiço, macho apresentando aumento de volume na região intermandibular. $B$ - Aumento de volume macio e flutuante na região sublingual da cavidade oral.

Foi coletado material através de punção aspirativa com agulha fina (PAAF), encaminhado ao laboratório de patologia clínica da Clínica Veterinária da PUCPR - Campus Toledo e identificado como saliva pelas características citológicas, de um líquido viscoso mucinoso, limpo, compatível com saliva. Como exame complementar foi realizado um hemograma, que revelou leucocitose com linfocitose. Após exame clínico do paciente, associado aos achados dos exames complementares, diagnosticou-se a mucocele da glândula sublingual direita.

Para o tratamento, a ser realizado na propriedade, elegeu-se o procedimento cirúrgico de marsupialização da rânula, conforme técnica sugerida por Radlinsky (2014). Realizou-se prémedicação com cloridrato de xilazina $(0,3 \mathrm{mg} / \mathrm{kg} /$ IM), com o animal contido em decúbito esternal, e em seguida realizou-se bloqueio anestésico com aplicação perineural de cloridrato de lidocaína $2 \%$ (1 mg/kg) sobre o nervo mandibular, localizado no forame mandibular em ambas hemi-arcadas.

Após o procedimento de antissepsia da cavidade oral com clorexidine $0,2 \%$, realizou-se incisão longitudinal de aproximadamente $5 \mathrm{~cm}$ na rânula (Figura 2), formando uma abertura através da qual foi possível drenar todo o conteúdo salivar acumulado. Em seguida foi realizada sutura das bordas da incisão da rânula na mucosa do assoalho bucal. Utilizou-se para a sutura fio monofilamentar absorvível (poliglactina 910) número 0 , com padrão simples contínuo. Objetivou-se, além de drenar o conteúdo salivar acumulado, manter um orifício na rânula para que esta se mantivesse aberta, favorecendo a drenagem da saliva para a cavidade oral.

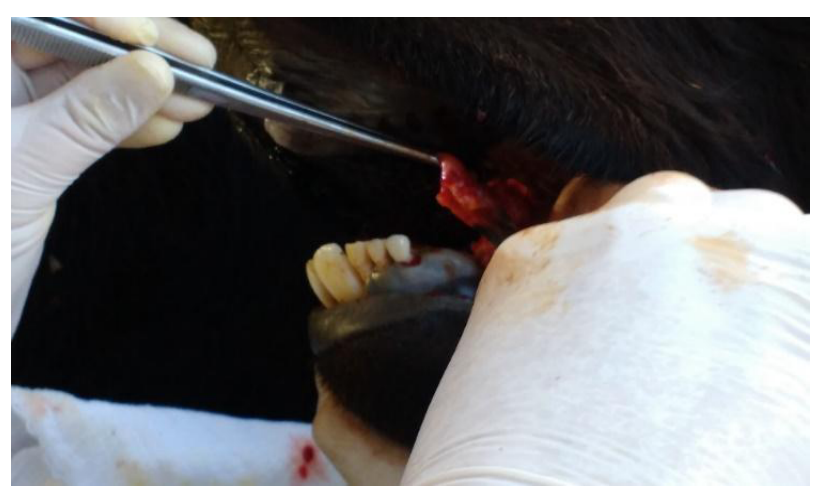

Figura 2 - Realização da incisão da rânula e formação de uma abertura.

Após a marsupialização da rânula, também realizou-se punção e aspiração do espaço intermandibular, objetivando-se drenar o restante do conteúdo salivar ainda retido na cavidade oral. Para este procedimento, utilizou-se agulha $40 \mathrm{x}$ 
12 acoplada a uma seringa de $20 \mathrm{ml}$, com prévia tricotomia e antissepsia com PVPI tópico 1\% no local.

Para o pós-operatório foi prescrita associação de benzilpenicilina G procaína e benzatina (22.000 $\mathrm{UI} / \mathrm{kg})$ + dihidroestreptomicina $(25 \mathrm{mg} / \mathrm{kg}) \mathrm{IM}$ a cada 48 horas, durante seis dias, e meloxicam $(0,6$ $\mathrm{mg} / \mathrm{kg} / \mathrm{IM} / \mathrm{SID}$ ) por cinco dias.

No dia seguinte ao procedimento cirúrgico, o paciente apresentava normorexia e normodipsia. O proprietário relatou que não houve recidiva até o animal ser destinado ao abate.

\section{Discussão}

A mucocele é considerada uma enfermidade rara em bovinos (Tobias, 2011), apesar de ser comum na clínica médica de pequenos animais (Radlinsky, 2014).

De acordo com Juergens et al. (1974) e Al Sadi (2013), quando um ducto salivar é danificado, a saliva pode se difundir para tecidos adjacentes e, tratando-se da glândula salivar sublingual, levar à formação de uma rânula, originando um aumento de volume translúcido e flutuante, assim como observado no presente relato.

A leucocitose causada pela linfocitose se associa com infecções crônicas, animais jovens, excitação, entre outras causas (Lopes et al., 2007), não elucidando a causa desse achado no paciente relatado.

O uso de aspiração por agulha fina auxilia no diagnóstico desta enfermidade, sendo observadas no aspirado proteínas e pouca celularidade, confirmando tratar-se apenas de saliva (Ikarashi et al., 1994).

A utilização da sialografia para o diagnóstico também é possível, porém torna-se uma técnica bastante trabalhosa e desnecessária (Hedlund e Fossum, 2007; Birchard e Sherding, 2008; Radlinsky, 2014), podendo se confirmar o diagnóstico a partir de sinais clínicos apresentados pelo animal, alterações no leucograma (leucocitose), exame histopatológico no caso de neoplasia de glândula salivar e estudos radiográficos.

O bloqueio perineural do nervo mandibular é utilizado quando se tem o objetivo de fazer intervenções gengivais e dentárias (Massone, 2011), não sendo utilizado na clínica de pequenos para correção de mucocele, mas podendo ser utilizado na clínica de grandes animais. Por não ser feita anestesia geral no paciente, torna-se importante fazer bloqueios anestésicos locais para o paciente não sentir dor durante o procedimento cirúrgico.

De acordo com Knecht (1996) e Pignone et al. (2009), como técnica a ser utilizada para a correção de mucocele, pode-se destacar drenagem do conteúdo, seguida da marsuapialização da glândula ou exérese de toda a glândula salivar acometida, estando de acordo com os autores a técnica realizada para a correção de tal afecção adotada no presente relato.

O uso de drenos após o procedimento também é sugerido por alguns autores quando se trata de mucocele cervical (Knecht, 1996; Hedlund, 2002; Radlinsky, 2014). No entanto, ainda que não tenham sido utilizados drenos no caso clínico apresentado, o paciente, 24 horas após o procedimento cirúrgico adotado, apresentou melhora sem recidiva.

\section{Conclusão}

A mucocele é uma afecção pouco diagnosticada na clínica de ruminantes, porém, de acordo com o presente relato, pode-se realizar o procedimento cirúrgico para correção a campo sem complicações pós-operatórias e com prognóstico favorável para a vida do animal, tornando-se uma prática acessível a médicos veterinários que trabalham no campo.

\section{Referências}

Al Sadi S. Cross and radiological studies of the salivary gland in cattle. Basra J Vet Res. 2013;12(1):65-75.

Birchard SJ, Sherding RG. Manual Saunders Clínica de pequenos animais. São Paulo: Roca; 2008. 2048 p.

Dias FGG, Pereira LF, Santilli J, Magalhães GM, Dias LGGG. Mucocele em cães. Encicl Biosfera. 2013;9(16):1534-43.

Dyce K, Sack W, Wensing CJG. Text book of veterinary anatomy. Philadelphia: Saunders Elsevier; 2010. 864 p. 
Hedlund CS. Surgery of digestive system. In: Fossum TW. Small Animal Surgery. St Louis: Mosby; 2002. p. 302-5.

Hedlund CS, Fossum TW. Surgery of the oral cavity and oropharynx. In: Fossum TW. Small Animal Surgery. St Louis: Mosby; 2007. p.339-371.

Ikarashi T, Inamura K, Kimura Y. Cystic lymphangioma and plunging ranula treated by OK-432 therapy: a report of two cases. Acta Otolaryngol Suppl. 1994;511:196-9.

Juergens T, Hjelm GK, Lange RL. Mandibular sialoadenectomy. Iowa State Univ Vet. 1974;36(3):94-8.

Knecht CD. Glândulas salivares. In: Bojrab MJ. Técnicas atuais em cirurgia de pequenos animais. São Paulo: Roca; 1996. p.188-91.

König HE, Sótonyi P, Liebich HG. Sistema digestório. In: König HE, Liebich HG. Anatomia dos animais domésticos - texto e atlas colorido. Porto Alegre: Artmed; 2011. p. 321-88.

Lopes STA, Biondo AW, Santos AP. Manual de Patologia Clínica. Santa Maria: UFSM; 2007. 107 p.

Massone F. Anestesiologia veterinária: farmacologia e técnicas: texto e atlas. Rio de Janeiro: Guanabara Koogan; 2011.428 p.

McDougall El. Studies on ruminant saliva. 1. The composition and output of sheep's saliva. Biochem J. 1948;43(1):99-109.
Nelson RW, Couto CG. Fundamentos de Medicina Interna de Pequenos Animais. Rio de Janeiro: Guanabara Koogan; 2001. p. 322-42.

Neville BW, Damm DD, Allen CM, Bouquot JE. Patologia oral e maxilofacial. Rio de Janeiro: Guanabara Koogan; 2004. 992 p.

Pignone VN, Faraco CS, Albuquerque PB, Recla G, Gianotti G, Contesini EA. Sialólito no ducto da glândula mandibular em cão. Acta Sci Vet. 2009;37(3):277-80.

Radlinsky MG. Cirurgia do sistema digestório. In: Fossum TW. Cirurgia de pequenos animais. Rio de Janeiro: Elsevier; 2014. p. 386-583.

Santana CL, Kowalesky J, Villamizar-Martinez LA, Nascimento NA, Fugita MS, Gioso MA. Mucocele salivar complexa em cão - relato de caso. Rev mv\&z. 2014;12(2):55-6.

Sisson S, Grossman JD, Getty R. The anatomy of the domestic animals. Philadelphia: Saunders; 1975. 2130 p.

Tobias KM. Manual de cirurgia de tecidos moles em pequenos animais. São Paulo: Roca; 2011. p. 417-24.

Tommasi AF. Diagnóstico em patologia bucal. São Paulo: Pancast; 2014. 480 p. 